\title{
Associations of Mental and Behavioral Problems among Children Exposed to Intimate Partner Violence Previously and Visits with Their Fathers Who Perpetrated the Violence
}

\author{
Sachiko Kita1,2, Megumi Haruna1*, Miku Yamaji', Masayo Matsuzaki'1, Kiyoko Kamibeppu² \\ ${ }^{1}$ Department of Midwifery and Women's Health, Division of Health Sciences and Nursing, Graduate School of Medicine, \\ The University of Tokyo, Tokyo, Japan \\ ${ }^{2}$ Department of Family Nursing, Division of Health Sciences and Nursing, Graduate School of Medicine, \\ The University of Tokyo, Tokyo, Japan \\ Email: *mharuna-tky@umin.ac.jp
}

How to cite this paper: Kita, S., Haruna, M., Yamaji, M., Matsuzaki, M. and Kamibeppu, K. (2017) Associations of Mental and Behavioral Problems among Children Exposed to Intimate Partner Violence Previously and Visits with Their Fathers Who Perpetrated the Violence. Open Journal of Nursing, 7, 361-377.

https://doi.org/10.4236/ojn.2017.73029

Received: February 6, 2017

Accepted: March 17, 2017

Published: March 20, 2017

Copyright () 2017 by authors and Scientific Research Publishing Inc. This work is licensed under the Creative Commons Attribution International License (CC BY 4.0).

http://creativecommons.org/licenses/by/4.0/

\begin{abstract}
Background: Intimate partner violence has long-term and negative effects on the health of mothers and children worldwide. This study aimed to identify the mental and behavioral effects of past exposure to intimate partner violence among children and examine their associations with the children's visits with their fathers who perpetrated the intimate partner violence. Methods: A cross-sectional study of women who had been abused by their intimate partners and had one or more children aged 4 - 18 years old was conducted from March 2015 to December 2016. Questionnaires were used to collect (1) demographic data about the mothers and children, (2) information about the children's visits with the mother's former partner (i.e., father), and (3) psychological data using the Hospital Anxiety and Depression Scale and the Child Behavior Checklist/4 - 18. Results: The average scores and rates of internalizing, externalizing, and total problems among the children who had been exposed to intimate partner violence were: 10.8 (SD = 10.4), 26 (51.0\%); 9.0 (SD = 9.0), 14 (27.5\%); and 26.3 $(\mathrm{SD}=21.5), 15(29.4 \%)$, respectively. Children's visits with fathers who were IPV perpetrators were significantly associated with the internalizing $(\mathrm{AOR}=$ 12.6, $\beta=0.56 ; p<0.05)$ and total problems scores (AOR $=17.9, \beta=0.48 ; p<$ $0.05)$. Conclusion: Attention should focus on traumatized children exposed to intimate partner violence, and thorough and cautious assessments and decisions regarding visits with their fathers who are IPV perpetrators are essential to safeguard and improve their mental and behavioral health.
\end{abstract}




\section{Keywords}

Child Abuse, Exposure to Violence, Intimate Partner Violence, Mental and Behavioral Health, Visitation

\section{Introduction}

Intimate partner violence (IPV) is a serious health concern, which includes psychological (e.g., constant intimidation, belittling, and humiliation), physical (e.g., slapping, beating, and kicking), and controlling behaviors (e.g., isolating a person from family and friends, and restricting access to financial and social resources), as well as sexual violence (e.g., forced sexual intercourse) [1]. The worldwide rate of women abused by their partners is $30.0 \%$ [2], and $23.7 \%$ among the Japanese female population [3]. Children's exposure to IPV, such as witnessing or being involved in violent conflicts between parents, can cause serious mental and behavioral health issues, including Posttraumatic Stress Disorder (PTSD), mood and anxiety disorders, aggressive behaviors, self-harm, and eating and sleeping problems [4] [5] [6] [7]. Children who have been exposed to IPV may have psychological challenges for a long time after they have been separated from the perpetrator of the violence, who is often an abusive father. Several studies [8] [9] [10] [11] [12] have reported that abused women who left their abusive partners continue to struggle with severe psychological symptoms, including PTSD, anxiety, depression, and low self-esteem, which persist for a long time afterwards. However, the little information is available about the psychological mental and behavioral health of children who have been exposed to IPV due to the limited number of research studies of this problem.

Children who visited their fathers, who had perpetrated IPV, after a divorce or separation might be negatively affected, specifically their mental and behavioral health. In general, children exposed to their parents' divorce tend to be less welladjusted emotionally, socially, and behaviorally, and exhibit symptoms, such as depression, anxiety, anger, a decline in school performance, and externalizing behaviors (e.g., aggressive and noncompliant behavior), than those in non-divorced families [13] [14] [15]. Children's adjustment after their parents' divorce has been reported to be significantly associated with certain parenting characteristics: (1) a sufficiently warm, supportive, and sensitive parenting style to meet their child's needs and (2) the use of clear and consistent expectations and discipline methods by both the custodial and non-custodial parents [14]. On the other hand, involving children in parental conflicts (e.g., encouraging a child's hostile feelings towards the other parent and allowing a child to become entangled in parental acrimony) is harmful to the child's adjustment [14]. Children exposed to IPV are more likely to be manipulated by fathers who are IPV perpetrators (e.g., fathers frequently make negative remarks to these children about their mothers and they use these children as a means to threaten the mothers). The children often feel as though they are caught in the middle of a tense situation between the 
parents. They have strong feelings of anger, sadness, guilt, confusion, and helplessness when they see their fathers (i.e., IPV perpetrators) after their parents' separation, which might exacerbate mental or behavioral health issues they might have [16] [17]. We hypothesized that children who had been exposed to IPV and then visited their fathers (the IPV perpetrators) after their parents' divorce would be more likely to have more adverse mental and behavioral problems than those who did not visit their fathers. The identification of these associations should help us understand and develop effective interventions and environments for traumatized children who have been exposed IPV in order to enhance their psychological health.

This study aimed to identify the mental and behavioral health issues of children who were exposed to IPV previously and their associations with the children's visits with their fathers who perpetrated the IPV.

\section{Methods}

\subsection{Study Design and Period}

We conducted a cross-sectional study from March 2015 to December 2016.

\subsection{Participants}

Women who had (a) one or more children 4 - 18 years old, (b) previous experience of being abused through IPV, (c) left the abusive partner, and (d) been living separately from the abusive partner were eligible for participation in this study. Women who had (a) a severe mental illness or were unable answer the study's questionnaire because of their difficult circumstances, or (b) a poor command of the Japanese language were excluded from the study. Eligible participants were chosen and recruited directly using a consent form by the staff of an IPV support center that agreed to cooperate with this study.

\subsection{Procedure}

First, we asked two non-profit IPV support centers to coordinate the recruitment of participants for this study and to collaborate with the researchers concerning other aspects of the study. The two centers, which are located in Tokyo, assist abused women, most of whom are IPV survivors. The centers' services include counseling, educational programs, peer, legal, and housing support, and cooperation with police, lawyers, and psychologists. Most of the IPV support staff are women and laypersons that have experienced IPV and received training and education about IPV support; one of them was a midwife. After the first two centers agreed to cooperate, their IPV support staff asked other IPV support centers across the country, including non-profit, government-sponsored, and private support centers to recruit eligible participants who visited their centers by mailing a document with an explanation of the study to the centers. The staff of the centers that agreed to cooperate with this study explained it to the women attending their centers and asked them directly if they wished to participate in it. After the women agreed to participate and signed consent forms the staff provided them with a que- 
stionnaire package with instructions to complete and return it to the staff of the center. The staff collected and mailed the completed questionnaires to the researchers. The questionnaire package included two questionnaires: one for the mother and another for the child. Women who had more than one child were provided with the corresponding number of questionnaires in order to obtain responses for the each of the children.

\subsection{Measures}

\subsubsection{Demographic Characteristics}

The mothers' and children's demographic data were collected. The demographic data for the mothers included age, marital status, previous living arrangement with the former partner who was abusive, nationality (and the former partner's nationality), educational attainment, employment status, household income, number of years of enduring abuse, the number of years after separating from the abusive partner, and the number of years living without the abusive partner. The children's characteristics included age, sex, birth order, birth weight, current weight, current height, school attendance (e.g., daycare, kindergarten, elementary school, junior high school, or senior high school), medical history, custody, and previous living arrangement with their abusive father.

\subsubsection{Children's Visits with Their Fathers (IV Perpetrators)}

The following information about the children's visits with their fathers who were identified IPV perpetrators was collected: (a) whether they were currently visiting their fathers, (b) how often they visited, and (c) their reactions after the visits. The children's reactions to the visits were assessed using these multiple response options: happy, sad, calm, same as always, confused, angry, sad, depressed, and/or aggressive.

\subsubsection{Types and Severity of IPV Experienced by the Mothers}

The types and of severity of the previous IPV episodes experienced by the mothers in the study were measured using the Japanese version of the Revised Conflict Tactics Scales Short Form (JCTS2F) [18]. The JCTS2F was translated and developed by Umeda and Kawakamiin 2014 [19], who reported it to have good reliability and concurrent validity using the Buss-Perry Aggression Questionnaire, the Violence against Women Screen, and the Kessler 6. The JCTS2F has 10 items that measure respondents' experiences of abuse in IPV situations and five subscales: psychological aggression, physical assault, injury, sexual coercion, and negotiation. We used the eight items corresponding to four of the subscales (i.e., psychological aggression, physical assault, injury, and sexual coercion) in this study to evaluate the types and severity of IPV that were experienced during the one-year period when the most severe abuse occurred. Responses to items that measure the frequency of violence during the one-year period range from 1 (never happened) to 7 (more than 20 times). The presence of IPV was defined as one or more incidents of violence, which were assessed via the eight items, with the following response options: 0 (no incidents) and 1 (one or more incidents). Cronbach's alpha $(\alpha)$ for the eight items was 0.81 . 


\subsubsection{Anxiety and Depressive Symptoms of the Mothers}

The current symptoms of anxiety and depression among the mothers were evaluated using the Japanese version of the Hospital Anxiety and Depression Scale (HADS) [20] [21]. The Japanese HADS has a two-factor structure (anxiety and depression) and consists of seven items for each scale. The range of the scores for each scale is 0 - 21 points, with higher scores indicating more adverse symptoms (i.e., higher symptoms of anxiety and depression) [20] [21]. A total score of 11 - 21 points (for both of the scales) indicate definite cases of anxiety and depression. The Japanese version of the HADS has been found to have good reliability and validity among Japanese samples in medical and educational settings [22]. The reliability of the HADs in the present study was acceptable (anxiety: $\alpha$ $=0.86$; depression: $\alpha=0.77$ ).

\subsubsection{Mental and Behavioral Health Problems among the Children}

Problematic behaviors among the children were assessed using the Japanese version of the Child Behavior Checklist (CBCL)/4 - 18. The CBCL has been translated into 64 languages and is widely used to assess behavior problems among children [23] [24]. The CBCL has 119 items and nine subscales: withdrawn behavior, somatic complaints, anxious/depressed behavior, social problems, thought problems, attention problems, delinquent behavior, aggressive behavior, and other problems. Three of the subscales (withdrawn behavior, somatic complaints, and anxious/depressed behavior) are categorized as internalizing problems, and two of the subscales (delinquent behavior and aggressive behavior) as externalizing problems. The total score (i.e., total problems) is calculated by summing all of the nine subscales. The responses to the item are rated as 0 (not true), 1 (somewhat or sometimes true), and 2 (very true or often true). Higher scores indicate mental or behavioral problem that are more severe. A cut-off point for the each subscale is used to determine whether the severity of behavior is in the clinical range or not. The Japanese version of the CBCL, which was developed by Itani et al. [23], was found to have good reliability and validity. Cronbach's alphas of all the subscales were acceptable: withdrawn behavior $=0.74$; somatic complaints $=0.80$; anxious $/$ depressed behavior $=0.90$; social problems $=0.68$; thought problems $=0.55$, attention problems $=0.75$, delinquent behavior $=0.73$; aggressive behavior $=0.91$; and other problems $=0.72$. Cronbach's alphas of the two core subscales and total score were also good: internalizing problems $=0.93$; externalizing problems $=0.92$; and total problems $=0.97$.

\subsection{Statistical Analyses}

Descriptive statistics were used to calculate: the demographic data of the mothers and children, information about the children's visits with their fathers, and scores on the JCTS2F (scores and rates of the presence of IPV), the Japanese version of the HADS (scores and rates of definite cases), and the Japanese version of the CB$\mathrm{CL}$ (scores and rates of problem behaviors in the clinical range). To compare the scores and rates on the CBCL between the children who were currently visiting their fathers and those who were not, Student's $t$ tests and Fisher's exact tests were 
used. The correlations between the scores on the CBCL and the other measures were analyzed. Finally, multivariate logistic regression analyses and multivariate regression analyses were conducted to identify the factors associated with the scores and rates on the CBCL (i.e., scores for internalizing, externalizing, and total problems). The ideal number of data was $76-118$ (the number of predictors $=3$ 10 ; anticipated effect size $=0.15$; desired statistical power level $=0.80$; probability level $=0.05$ ) according to the sample size calculation for multiple regression. The statistical analyses were conducted using the Statistical Package for Social Sciences (SPSS) version 23.0 for Windows

\subsection{Ethical Considerations}

The study's protocol was approved by the ethical committee of the university with which several of the authors were affiliated. The participants were informed that this survey was anonymous, they could withdraw from the study at any time, and their data would be protected by storing it in a locked container. Information regarding the availability of psychiatrists, pediatric psychiatrists, and professional IPV counselors was provided for all the participants in case they wished to visit with them.

\section{Results}

A total of 69 women were recruited for this study; eight women were excluded because they were judged to be mentally impaired, and therefore, unable to participate. Of the 61 women remaining, 60 (98.4\%) agreed to participate and 38 (62.3\%) completed the questionnaire. Finally, data from 38 mothers and 51 children were used for the analyses.

\subsection{Participants' Characteristics}

The average age of the mothers was 42.8 years old $(\mathrm{SD}=5.6$, range $=33-54)$. All of the participants were Japanese $(n=38 ; 100 \%)$ and the majority was college or junior university graduates $(n=21 ; 55.3 \%)$. Full-time workers comprised $31.4 \%$ of the sample $(\mathrm{n}=12)$, household income ranged from 0 to 2.99 million yen $(\mathrm{n}=$ $7 ; 18.9 \%) ; 15.8 \%$ of the mothers were unemployed and/or receiving welfare; $71.1 \%$ were divorced from the abusive ex-partner; and $23.7 \%$ were not divorced from the ex-partner. Regarding previous IPV experience, all of the mothers had experienced psychological aggression $(\mathrm{n}=38 ; 100 \%)$ and the majority had experienced physical assault ( $n=29 ; 76.3 \%)$, injuries $(n=30 ; 78.9 \%)$, and sexual coercion $(n=27$; $71.1 \%$ ) by their former partners. The total number of years of abuse by their partner, years since they separated from the abusive partner, and years of living separately were $9.5(\mathrm{SD}=5.7$; range $=0-25), 6.9(\mathrm{SD}=5.2$; range $=1-19)$, and 6.8 $(\mathrm{SD}=5.5$; range $=1-19)$, respectively. The average scores for the HADS were: anxiety $=10.6(\mathrm{SD}=5.2)$, depression $=7.8(\mathrm{SD}=4.5)$; the clinical cases of anxiety and depression were18 $(\mathrm{SD}=47.4)$ and $12(\mathrm{SD}=31.6)$, respectively (Table 1$)$.

The average age of the children in this study was 11.47 years $(\mathrm{SD}=4.3$, range: 
Table 1. Demographic characteristics among the mothers ${ }^{\mathrm{a}}(\mathrm{n}=38)$.

\begin{tabular}{|c|c|c|c|}
\hline Age & n (\%) & Mean $\left(\mathrm{SD}^{\mathrm{b}}\right)$ & Range \\
\hline & & $42.84(5.61)$ & $3-54$ \\
\hline \multicolumn{4}{|l|}{ Marital status $^{c}$} \\
\hline Divorced & $27(71.1)$ & & \\
\hline Non-divorced & $9(23.7)$ & & \\
\hline Missing & $2(5.3)$ & & \\
\hline \multicolumn{4}{|l|}{ Used to live with the husband ${ }^{d}$} \\
\hline Yes & $37(97.4)$ & & \\
\hline No & $1(2.6)$ & & \\
\hline \multicolumn{4}{|l|}{ Nationality } \\
\hline Japanese & $38(100.0)$ & & \\
\hline \multicolumn{4}{|l|}{ Partner's nationality } \\
\hline Japanese & $35(92.1)$ & & \\
\hline \multicolumn{4}{|l|}{ Educational attainment } \\
\hline Junior high school & $1(2.6)$ & & \\
\hline Senior high school & $5(13.2)$ & & \\
\hline College/Junior university & $21(55.3)$ & & \\
\hline University & $8(21.1)$ & & \\
\hline Graduate school & $3(7.9)$ & & \\
\hline \multicolumn{4}{|l|}{ Working status } \\
\hline Full-time worker & $12(31.4)$ & & \\
\hline Contract worker & $6(15.8)$ & & \\
\hline Part-time worker & $7(18.4)$ & & \\
\hline Housewife & $1(2.6)$ & & \\
\hline Student & $1(2.6)$ & & \\
\hline Non-working & $6(15.8)$ & & \\
\hline Be on welfare & $6(15.8)$ & & \\
\hline \multicolumn{4}{|l|}{ Household income } \\
\hline 0 - 2.99 million yen & $7(18.9)$ & & \\
\hline 3 - 4.99 million yen & $2(5.3)$ & & \\
\hline 5 - 6.99 million yen & $2(5.3)$ & & \\
\hline $7-8.99$ million yen & $1(2.6)$ & & \\
\hline Over 9 million yen & $4(10.5)$ & & \\
\hline On welfare & $2(5.3)$ & & \\
\hline Missing & $20(52.6)$ & & \\
\hline \multicolumn{4}{|l|}{$\operatorname{HADS}(\mathrm{n}=36)^{\mathrm{e}}$} \\
\hline Anxiety score & & $10.58(5.23)$ & $1-19$ \\
\hline Anxiety identified ${ }^{\mathrm{f}}$ & $18(47.4)$ & & \\
\hline
\end{tabular}




\section{Continued}

\begin{tabular}{|c|c|c|c|}
\hline Depression score & & $7.75(4.46)$ & $0-15$ \\
\hline Depression identified ${ }^{\mathrm{f}}$ & $12(31.6)$ & & \\
\hline Years to be abused by the husband & & $9.49(5.70)$ & $0-25$ \\
\hline Years after separation ${ }^{g}$ & & $6.92(5.17)$ & $1-19$ \\
\hline Years during living separately ${ }^{\mathrm{h}}$ & & $6.81(5.50)$ & $1-19$ \\
\hline \multicolumn{4}{|l|}{ Abuse experience } \\
\hline Psychological aggression ${ }^{j}$ & $38(100.0)$ & $11.19(2.84)$ & $5-14$ \\
\hline Physical assault ${ }^{j}$ & $29(76.3)$ & $7.37(4.27)$ & $2-14$ \\
\hline Injury & $30(78.9)$ & $6.43(3.31)$ & $2-14$ \\
\hline Sexual coercion & $27(71.1)$ & $6.89(4.50)$ & $2-14$ \\
\hline
\end{tabular}

${ }^{a}$ Mothers who used to be abused by their (ex)husband and already separated; ${ }^{b}$ Standard Deviation; ${ }^{\mathrm{c} C u r r e n t}$ marital status with their husband abused; ${ }^{\mathrm{d}}$ The husbands who had perpetrated intimate partner violence against the mothers; ${ }^{\mathrm{e} H o s p i t a l}$ Anxiety and Depression Scale; ${ }^{\mathrm{f}}$ The rate was calculated using the cut-off point (over 11) of the HADS; ${ }^{\mathrm{g} Y e a r s}$ after separating the husband who had perpetrated IPV; ${ }^{\text {hY }}$ ears during living separately with the husband who had perpetrated IPV; iThe severity of IPV was evaluated using the Conflict Tactics Scale Short Form; ${ }^{j}$ The rate was the presence of an IPV-related act (one or more incidences).

$4-18)$, and the majority was $7-12$ years old $(n=20 ; 39.2 \%)$, boys $(n=33$; $64.2 \%)$, and the oldest brother or sister $(n=31 ; 60.8 \%)$. A total of $94.1 \%$ of the children $(n=48)$ were currently attending a school, $31.3 \%$ had a previous medical problem, such as allergies $(\mathrm{n}=6)$ (e.g., atopic dermatitis and asthma), bacterial pneumonia $(\mathrm{n}=1)$, uterus myoma $(\mathrm{n}=1)$, autotoxemia $(\mathrm{n}=1)$, attention-deficit hyperactivity disorder (ADHD) $(\mathrm{n}=2)$, irritable bowel syndrome $(\mathrm{n}=1)$, a long hospitalization due to unexplained high fever $(n=1)$, migraine headache $(n=1)$, and mother-infant separation anxiety disorder $(\mathrm{n}=1)$. In addition, $42(82.4 \%)$ mothers had custody of their children. Almost all of the children $(n=46 ; 90.2 \%)$ previously lived with their fathers in the same house and the average number of years of living with their fathers was 6.23 years $(S D=3.6$; range $=0-16)($ Table 2).

\subsection{Children's Visits with Their Fathers (IPV Perpetrators)}

Nineteen (37.3\%) children in the study were currently visiting their fathers. Their frequency of visits was, on average, 2.2 visits per year $(\mathrm{SD}=2.3$; range $=0.5$ 6.5). The most frequent reactions among the children after they visited their fathers were: same as always $(\mathrm{n}=6 ; 33.3 \%)$, aggressive $(\mathrm{n}=6 ; 33.3 \%)$, angry $(\mathrm{n}=$ 5; 27.7\%), happy ( $n=5 ; 27.7 \%)$, and confused $(n=4 ; 22.2 \%)$ (Table 3$)$.

\subsection{Children's Mental and Behavioral Problems}

The children's average scores and the rates of scores in the clinical range on the Japanese version of the CBCL were: withdrawn behavior $=2.8(\mathrm{SD}=3.0)$ and 6 $(11.8 \%)$; somatic complaints $=2.5(\mathrm{SD}=3.3)$ and $12(23.5 \%)$; anxious/depressed $=5.7(\mathrm{SD}=5.7)$ and $9(17.6 \%)$; social problems $=2.8(\mathrm{SD}=2.6)$ and $5(9.8 \%)$; thought problems $=1.3(\mathrm{SD}=1.7)$ and $15(29.4 \%)$; attention problems $=4.5(\mathrm{SD}$ 
Table 2. Demographic characteristics among the children ${ }^{a}(n=51)$.

\begin{tabular}{|c|c|c|c|}
\hline & $\mathrm{n}(\%)$ & Mean (SD) & Range \\
\hline Age & & $11.47(4.34)$ & $4-18$ \\
\hline $4-6$ & $8(15.7)$ & & \\
\hline $7-12$ & $20(39.2)$ & & \\
\hline $13-15$ & $10(19.6)$ & & \\
\hline $16-18$ & $13(25.1)$ & & \\
\hline \multicolumn{4}{|l|}{ Sex } \\
\hline Boy & $33(64.7)$ & & \\
\hline Girl & $18(35.3)$ & & \\
\hline \multicolumn{4}{|l|}{ Birth order } \\
\hline 1 & $31(60.8)$ & & \\
\hline 2 & $15(29.4)$ & & \\
\hline 3 & $4(7.8)$ & & \\
\hline 4 & $1(2.0)$ & & \\
\hline Birth weight (g) & & $3101(445.10)$ & $2096-4022$ \\
\hline Current weight (kg) & & $37.44(2.34)$ & $12-78$ \\
\hline Current height $(\mathrm{cm})$ & & $144.63(23.70)$ & $95-182$ \\
\hline Attending school ${ }^{\mathrm{b}}$ & $48(94.1)$ & & \\
\hline \multicolumn{4}{|l|}{ Medical history } \\
\hline No & $34(66.7)$ & & \\
\hline Yes $^{\mathrm{cd}}$ & $16(31.3)$ & & \\
\hline Missing & $1(2.0)$ & & \\
\hline \multicolumn{4}{|l|}{ Custody } \\
\hline Mother & $42(82.4)$ & & \\
\hline Father & $1(2.0)$ & & \\
\hline Under conciliation adjudication & $6(11.8)$ & & \\
\hline Missing & $2(3.8)$ & & \\
\hline \multicolumn{4}{|l|}{ Used to live with their father } \\
\hline No & $3(5.9)$ & & \\
\hline Yes & $46(90.2)$ & & \\
\hline Missing & $2(3.9)$ & & \\
\hline Years CLFP ${ }^{e}$ & & $6.22(3.60)$ & $0-16$ \\
\hline $0-4$ & $14(27.5)$ & & \\
\hline $5-9$ & $21(41.2)$ & & \\
\hline $10-14$ & $4(7.8)$ & & \\
\hline $15-18$ & $2(3.9)$ & & \\
\hline Missing & $10(19.6)$ & & \\
\hline
\end{tabular}

${ }^{\mathrm{a}}$ Children who had exposed to intimate partner violence in the past; ${ }^{\mathrm{b}}$ Attending daycare, kindergarten, elementary school, and junior and senior high school; ${ }^{\circ}$ Their medical histories include: allergic diseases $(n=6)$ (e.g., atopic dermatitis, and asthma); Bacterial pneumonia $(\mathrm{n}=1)$; Uterus myoma $(\mathrm{n}=1)$; Autotoxemia $(\mathrm{n}$ $=1)$; Attention-deficit hyperactivity disorder (ADHD) $(n=2)$; Irritable bowel syndrome $(n=1)$; Long hospitalization due to unexplained high fever $(\mathrm{n}=1)$; Migraine headache $(\mathrm{n}=1)$; Mother-infant separation anxiety disorder $(n=1) ;{ }^{\mathrm{d}}$ Multiple responses were available; ${ }^{\mathrm{e}}$ Number of years the child lived with the father in the past. 
Table 3. Variables regarding the children's ${ }^{\mathrm{a}}$ visits to their father ${ }^{\mathrm{b}}(\mathrm{n}=51)$.

\begin{tabular}{cccc}
\hline & $\mathrm{n}(\%)$ & Mean (SD) & Range \\
\hline Currently visiting their father & & \\
No & $30(58.8)$ & \\
Yes & $19(37.3)$ & \\
Missing & $2(3.9)$ & \\
Frequency of visiting their father per year $(\mathrm{n}=15)$ & & \\
Reactions after visiting their father $(\mathrm{n}=18)^{\mathrm{cd}}$ & & \\
Happy & $5(27.7)$ & \\
Fun & $2(11.1)$ & \\
Calmed & $1(5.5)$ & \\
Same as always & $6(33.3)$ & \\
Confused & $4(22.2)$ & \\
Angry & $5(27.7)$ \\
Sad & $2(11.1)$ \\
Depressed & $3(16.7)$ \\
Aggressive & $6(33.3)$ \\
\hline
\end{tabular}

${ }^{a}$ Children who had exposed to intimate partner violence in the past; ${ }^{b}$ Father who used to perpetrate intimate partner violence and already separated from their mothers; ${ }^{\circ}$ Their mother answered the question; ${ }^{\mathrm{d}}$ Multiple responses were available.

$=3.5)$ and $10(19.6 \%)$; delinquent behavior $=1.9(\mathrm{SD}=2.6)$ and $8(15.7 \%)$; aggressive behavior $=7.1(\mathrm{SD}=6.9)$ and $8(15.7 \%)$; and other problems $=6.2(\mathrm{SD}$ = 5.0) (no cut-off point). Three groups consisting of 26 (51.0\%), 14 (27.5\%), and 15 (29.4\%) children were classified as being in the clinical range of scores for internalizing, externalizing, and total problems, respectively (Table 4).

\subsection{Comparison of the CBCL Scores and Clinicalrates between the Children Who Visited Their Fathers and Those Who Did Not}

The average scores for the following subscales of the CBCL among the children who visited their fathers were significantly higher than those who did not visit their fathers: withdrawn behavior ( 4.8 versus $1.5, p=0.00$ ); somatic complaints (4.1 versus $1.5, p=0.03$ ); anxious/depressed behavior (8.4 versus $3.8, p=0.02$ ), thought problems (2.1 versus $0.77, p=0.02$ ); attention problems ( 6.5 versus 3.4 , $p=0.00)$; other problems (7.9 versus $4.9, p=0.05)$; internalizing problems (17.4 versus $6.8, p=0.00$ ); and total problems (37.6 versus $19.1, p=0.00$ ). In addition, The rate of children with scores in the clinical range for withdrawn behavior (31.6\% versus $0.0 \%, p=0.00)$, thought problems ( $52.6 \%$ versus $16.7 \%, p=0.01$ ), delinquent behavior $(31.6 \%$ versus $6.7 \%, p=0.00)$, internalizing problems $(73.7 \%$ versus $33.3 \%, p=0.01$ ), externalizing problems ( $47.4 \%$ versus $16.7 \%, p=0.03$ ), and total problems $(57.9 \%$ versus $13.3 \%, p=0.00)$ were significantly higher among the children who were visiting their fathers than those were not visiting them (Table 4). 
Table 4. Comparisons of the $\mathrm{CBCL}^{\mathrm{a}}$ scores and rates between the children's visits to their father or those without visiting ${ }^{\mathrm{b}}$ ( $\mathrm{n}=$ 51).

\begin{tabular}{|c|c|c|c|c|c|c|c|c|c|}
\hline & $\begin{array}{c}\text { Mean }(\mathrm{SD}) \\
\mathrm{n}=51\end{array}$ & $\begin{array}{l}\text { Range } \\
\mathrm{n}=51\end{array}$ & $\begin{array}{c}\text { Prevalence }^{c} \\
\text { n (\%) }\end{array}$ & $\begin{array}{c}\text { Children } \\
\text { visiting father } \\
\mathrm{n}=19\end{array}$ & $\begin{array}{l}\text { Children } \\
\text { no visiting } \\
\mathrm{n}=30\end{array}$ & $p$ value $^{\mathrm{d}}$ & $\begin{array}{c}\text { Children } \\
\text { visiting father } \\
n=19^{\mathrm{b}}\end{array}$ & $\begin{array}{c}\text { Children } \\
\text { no visiting } \\
\mathrm{n}=30\end{array}$ & $p$ value $^{\mathrm{e}}$ \\
\hline & & & $\mathrm{n}=51$ & mean $(\mathrm{SD})$ & mean $(\mathrm{SD})$ & & n (\%) & n (\%) & \\
\hline Withdrawn & $2.78(2.96)$ & $0-13$ & $6(11.8)$ & $4.78(3.62)$ & $1.53(1.63)$ & 0.001 & $6(31.6)$ & $0(0.0)$ & 0.002 \\
\hline Somatic complaints & $2.49(3.32)$ & $0-13$ & $12(23.5)$ & $4.06(4.50)$ & $1.50(1.83)$ & 0.028 & $6(31.6)$ & $5(16.7)$ & 0.072 \\
\hline Anxious/depressed & $5.66(5.74)$ & $0-21$ & $9(17.6)$ & $8.39(7.18)$ & $3.78(3.00)$ & 0.017 & $6(31.6)$ & $3(10.0)$ & 0.298 \\
\hline Social problems & $2.75(2.63)$ & $0-10$ & $5(9.8)$ & $3.68(3.09)$ & $2.17(2.26)$ & 0.074 & $3(15.8)$ & $2(6.7)$ & 0.363 \\
\hline Thought problems & $1.27(1.73)$ & $0-7$ & $15(29.4)$ & $2.13(1.89)$ & $0.77(1.45)$ & 0.006 & $10(52.6)$ & $5(16.7)$ & 0.012 \\
\hline Attention problems & $4.54(3.51)$ & $0-13$ & $10(19.6)$ & $6.50(3.36)$ & $3.20(3.07)$ & 0.001 & $6(31.6)$ & $3(10.0)$ & 0.072 \\
\hline Delinquent behavior & $1.91(2.55)$ & $0-13$ & $8(15.7)$ & $2.63(2.56)$ & $1.43(2.57)$ & 0.119 & $6(31.6)$ & $2(6.7)$ & 0.002 \\
\hline Aggression behavior & $7.09(6.85)$ & $0-32$ & $8(15.7)$ & $8.84(6.59)$ & $6.00(7.09)$ & 0.167 & $4(21.1)$ & $4(13.3)$ & 0.694 \\
\hline Other problems & $6.21(5.04)$ & $1-16$ & N/A & $7.94(5.25)$ & $4.91(4.70)$ & 0.048 & N/A & N/A & N/A \\
\hline Internalizing problems & $10.83(10.43)$ & $0-43$ & $26(51.0)$ & $17.42(13.17)$ & $6.78(6.15)$ & 0.004 & $14(73.7)$ & $10(33.3)$ & 0.009 \\
\hline Externalizing problems & $9.00(8.99)$ & $0-45$ & $14(27.5)$ & $11.47(17.85)$ & $7.44(9.24)$ & 0.135 & $9(47.4)$ & $5(16.7)$ & 0.027 \\
\hline Total problems & $26.25(21.48)$ & $1-84$ & $15(29.4)$ & $37.63(23.61)$ & $19.12(17.85)$ & 0.004 & $11(57.9)$ & $4(13.3)$ & 0.002 \\
\hline
\end{tabular}

${ }^{a}$ Child Behavior Checklist for $4-18$ years; ${ }^{b}$ Children who are currently visiting their father who perpetrated intimate partner violence and already separated

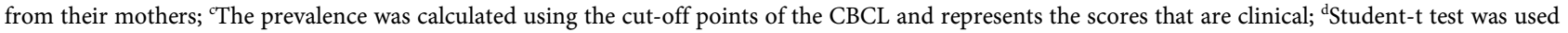
to compare the scores between the both groups; ${ }^{\mathrm{e}}$ Fisher's exact test was used to compare the prevalence of the children classified as clinical using the cut-off points of the CBCL.

\subsection{Factors Related to the Children's CBCL Scores and Rates}

As shown in Table 5 , the score and dichotomous variable $(0=$ non-clinical, $1=$ clinical), internalizing problems was significantly associated with: child's age ( $\beta$ $=0.42)$, mother's age $(\beta=-0.32)$, currently visits to their father $(\beta=0.56)$, mother's anxiety $(\beta=0.63)$, and the number of years the child lived with the father in the past $(\beta=-0.32)$. The adjusted odds ratios (AOR) were as follows: child's age $(\mathrm{AOR}=1.4)$, mother's age $(\mathrm{AOR}=0.7)$, the total score for the JCTS2F (AOR $=1.1)$, and currently visits to their father $(\mathrm{AOR}=12.6)$. None of the variables were significantly associated with the score and dichotomous variable $(0=$ nonclinical, $1=$ clinical), externalizing problems. Regarding the score and dichotomous variable $(0=$ non-clinical, $1=$ clinical $)$ of total problems, currently visits to their father $(\beta=0.48)$, and mother's anxiety $(\beta=0.48)$ were significantly associated with the score, and only currently visits to their father $(\mathrm{AOR}=17.9)$. (Table 5) was for the dichotomous variables.

\section{Discussion}

This study reported findings about the mental and behavioral health of a sample of children who had been exposed to IPV in the past. The children's visits to their fathers who were IPV perpetrators were significantly associated with having behavioral problems, such as internalizing and total problems $(\beta=0.56$; $\mathrm{AOR}=$ 12.6) and total problems $(\beta=0.48$; $\mathrm{AOR}=17.9)$, as measured on the CBCL, 
Table 5. Related factors for the $\mathrm{CBCL}^{\mathrm{a}}$ scores and rates among the children $(\mathrm{n}=49)^{\mathrm{b}}$.

\begin{tabular}{|c|c|c|c|c|c|c|c|c|c|c|c|c|c|c|}
\hline & \multicolumn{5}{|c|}{ Internalizing problems ${ }^{c}$} & \multicolumn{5}{|c|}{ Externalizing problems ${ }^{\mathrm{d}}$} & \multicolumn{4}{|c|}{ Total problems ${ }^{\mathrm{e}}$} \\
\hline & $\mathrm{AOR}^{\mathrm{ef}}$ & $p^{g}$ & $\beta^{\text {h }}$ & $p^{\mathrm{i}}$ & $\operatorname{VIF}^{j}$ & $\mathrm{AOR}^{\mathrm{ef}}$ & $p^{g}$ & $\beta^{\text {h }}$ & $p^{i}$ & VIF $^{j}$ & $\mathrm{AOR}^{\mathrm{ef}}$ & ef $p^{g}$ & $\beta^{\text {h }}$ & $p^{\mathrm{i}} \mathrm{VIF}^{\mathrm{j}}$ \\
\hline Child age & 1.37 & 0.04 & 0.42 & 0.01 & 1.51 & 1.03 & 0.77 & 0.03 & 0.86 & 1.53 & 1.38 & 0.05 & 0.26 & 0.131 .51 \\
\hline Mother age & 0.73 & 0.03 & -0.32 & 0.07 & 1.89 & 1.04 & 0.68 & 0.01 & 0.95 & 1.89 & 0.83 & 0.21 & -0.23 & 0.231 .88 \\
\hline $\begin{array}{l}\text { Total score } \\
\text { of CTS2F }\end{array}$ & 1.10 & 0.04 & 0.19 & 0.21 & 1.53 & 1.01 & 0.79 & 0.18 & 0.37 & 1.53 & 1.03 & 0.52 & 0.31 & 0.071 .53 \\
\hline $\begin{array}{c}\text { Currently } \\
\text { visiting } \\
\text { father }^{\mathrm{k}}\end{array}$ & 12.56 & 0.02 & 0.56 & 0.00 & 1.13 & 4.72 & 0.06 & 0.27 & 0.13 & 1.16 & 17.90 & 0.00 & 0.48 & 0.001 .13 \\
\hline $\begin{array}{l}\text { Mother's } \\
\text { anxiety }\end{array}$ & 1.31 & 0.07 & 0.63 & 0.02 & 2.28 & 1.03 & 0.83 & 0.22 & 0.38 & 2.34 & 1.30 & 0.08 & 0.48 & $\begin{array}{lll}0.03 & 2.28\end{array}$ \\
\hline $\begin{array}{c}\text { Mother's } \\
\text { depression }^{\mathrm{m}}\end{array}$ & 0.91 & 0.46 & -0.33 & 0.07 & 1.97 & 1.05 & 0.63 & -0.06 & 0.80 & 2.05 & 0.99 & 0.93 & -0.20 & 0.311 .97 \\
\hline Years CLFP ${ }^{n}$ & 0.90 & 0.39 & -0.38 & 0.01 & 1.18 & 0.98 & 0.83 & -0.07 & 0.67 & 1.18 & 0.76 & 0.13 & -0.30 & 0.051 .18 \\
\hline Adjusted $\mathrm{R}^{20}$ & & & 0.42 & & & & & 0.13 & & & & & 0.28 & \\
\hline
\end{tabular}

${ }^{\mathrm{a} C h i l d ~ B e h a v i o r}$ Checklist for $4-18$ years; ${ }^{\mathrm{b}}$ Children who are currently visiting their father who used to perpetrate intimate partner violence and already separated from their mothers; 'Internalizing problems = Withdrawn + Somatic complaints + Anxious/depressed; ${ }^{\mathrm{d} E x t e r n a l i z i n g}$ problems $=$ Delinquent behavior + Aggressive behavior; Total problems $=$ the sum of the scores of all the nine subscales of the CBCL; ${ }^{\mathrm{e}} \mathrm{Ad}-$ justed odds ratios calculated by multivariable logistic regression analysis; ${ }^{\mathrm{f}}$ The dependent variable: $0=$ nonclinical, 1 = clinical; ${ }^{\mathrm{g}} p$ values calculated by multivariable logistic regression analysis; ${ }^{\mathrm{h}}$ Standardized regression coefficients calculated by multivariable regression analysis; ${ }^{i} p$ values calculated by multivariable regres-

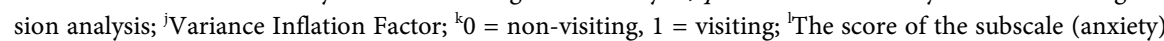
of the Hospital Anxiety and Depression Scale; ${ }^{\mathrm{m}}$ The score of the subscale (depression) of the Hospital Anxiety and Depression Scale; ${ }^{\mathrm{n} T h e}$ number of years the child lived with the father in the past; ${ }^{\circ}$ Adjusted $\mathrm{R}^{2}$ calculated by multivariable regression analysis.

after adjusting for the other children's and mothers' variables (e.g., age, the severity of previous IPV, and the mother's mental status).

The average scores on the CBCL and the rates of problematic behaviors (internalizing, externalizing, and total problems scores) among the children who had been exposed to IPV were: internalizing problems $=10.8(\mathrm{SD}=10.4), 51.0 \%$; externalizing problems $=9.0(\mathrm{SD}=9.0), 27.5 \%$; total problems $=26.3(\mathrm{SD}=21.5)$, $29.4 \%$. All the average scores in this study were much higher than those reported in a sample of Japanese children aged $4-18(\mathrm{~N}=5159)$ from the general population: internalizing problems $=3.1-3.8(\mathrm{SD}=4.2-4.8)$; externalizing problems $=$ $3.1-5.3(\mathrm{SD}=4.3-5.6)$; total problems $=11.7-16.1(\mathrm{SD}=13.4-14.5)$ [23]. Previous studies [6] [25] [26] have reported that children exposed to IPV have severe mental and behavioral problems, such as high levels of anxiety, social withdrawal, depression, aggressiveness, suicidal ideation, and reduced social competence. These findings indicate that children who have been exposed to IPV continue to manifest their suffering from the past traumatic events with behavioral difficulties six years, on average, after their exposure to IPV. Bancroft [16] has cautioned that recovering from the psychological trauma and injury related to exposure to IPV among children takes a long time after they separate from their ab- 
usive fathers, and that intensive and continuous psychological treatment and counseling is necessary. Healthcare professionals should recognize the importance of increasing attention to the mental and behavioral health of children who have been exposed to IPV and to providing sufficient psychological interventions and care for them in order to facilitate their recovery from the trauma.

This study found that children's visits to their fathers who perpetrated IPV were a risk factor for aggravating their mental and behavioral health problems, such as internalizing and total problems, as measured by the CBCL. A review study [25] reported that $72.7 \%$ of children exposed to IPV witnessed psychological IPV and that $90.1 \%$ were exposed to physical IPV, such as hearing verbal threats and seeing slapping and kicking. In addition, the co-existence of IPV and child abuse is quite high $(60 \%$ - 75\%) [27], and fathers are the most common perpetrators [17] [25]. Given these circumstances, traumatized children are likely to remember and re-experience past traumatic events when they visit their fathers who threatened them in the past. Furthermore, this study found that the children who were currently visiting their fathers reported feeling not only aggressive (11.8\%), angry (9.8\%), and confused (7.8\%), but also the same as always $(11.8 \%)$ and happy (9.8\%) after visiting their fathers. Bancroft and Silverman [17] reported that children whose mothers divorced their biological fathers, who were abusive, frequently experienced complex and ambivalent feelings about their father. Their feelings were possibly due to their deep sadness, loss, guilt, loneliness, anger, and helplessness related to the consequences of the family's conflicts (e.g., divorce and living separately), past traumatic experiences, and abusive fathers, which may have caused more confusion and emotional distress among these children. These findings indicate that the possibility and conditions of children's visits with their fathers who are abusers should be determined with caution, and monitored through continuous observation of the child's psychological health and situations surrounding those who have been exposed to IPV.

\subsection{Clinical Implications}

This study suggests attention should be focused on the serious and long-term effects of exposure to IPV on the mental and behavioral health of children. The results of this study have demonstrated that $51.0 \%$ of the children who exposed to IPV previously have been suffering from internalization problems and $27.5 \%$ $29.3 \%$ for externalizing and total problems at averagely six years later after separating their fathers who perpetrated IPV. In Japan, few healthcare professionals pay attention to children after separating them from their abusers because they move them to a safe place. However, the results of this study indicate that the psychological trauma of children's past exposure to IPV does not heal for a long time after their separation from the abuser. Intensive and continuous psychological interventions with interdisciplinary collaboration between healthcare professionals (e.g., pediatric nurses, midwives, public health nurses, pediatric psychiatrist, pediatricians, and clinical psychotherapists), mothers and other family members, educational professionals (e.g., teachers, and school counselors), and IPV profes- 
sionals (e.g., IPV counselors) are essential for traumatized children to hasten their recovery and improve their psychological health.

This study's results also suggest that the negative impact of visiting fathers identified as IPV perpetrators on children's mental and behavioral health, such as internalizing problems $(\beta=0.56$; AOR $=12.6)$ and total problems $(\beta=0.48$; AOR $=17.9$ ), should be acknowledged. A previous study investigating the quality of cooperation in divorced families [28] found that the level of co-parenting quality was lowest in the group with coercive and controlling IPV than in the non-IPV group. Additionally, less importance on the father-child relationship was reported in the IPV group. All professionals involved in IPV, such as healthcare professionals, legal professionals, and IPV counselors should understand that those children's visits with fathers who have been identified as abusers might exacerbate their mental and behavioral health problems. Careful and thorough assessments of traumatized children who have been exposed to IPV should be an essential first step before considering the possibility of children's visits with fathers who are known abusers. Such careful attitudes and procedures are required for cases of IPV in order to promote the safety and improve the health of the traumatized children.

\subsection{Limitations and Future Research Directions}

This study has some limitations. First, the characteristics of the participants in this study might be biased primarily due to the study's exclusion criteria (i.e., having a severe mental illness or a family situation that was so difficult, it precluded the mother's participation). The psychological health of the participants in this study might be different (i.e., better) compared to abused women in the general population. Thus, the results of this study might be biased due to the underrepresented characteristics of the sample (e.g., the severity of previous IPV and the psychological health of the mothers and children). The second limitation is the study's small sample size. Despite the researchers' attempts to recruit as many eligible participants as possible during the one and one-half year study period, the majority of potential participants (i.e., abused women) experienced severe levels of distress (e.g., depression) and could not be recruited. Thus, the small sample size might have resulted in $\beta$ errors and affected the results of this study. Third, this study used a cross-sectional design. Therefore, causal relationships between the variables cannot be inferred.

Despite these limitations, this study is the first to identify mental and behavioral health issues among children who were exposed to IPV, and confirm their associations with the children's visits with their fathers who perpetrated the IPV.

\section{Conclusion}

This study examined the mental and behavioral effects of children's exposure to IPV and their associations with the children's visits with their fathers who were known as abusers. The results of this study indicated that the children who are exposed to IPV tended to have adverse mental and behavioral effects (e.g., interna- 
lizing and externalizing problems), and that visiting their fathers who were IPV perpetrators increased the risk of exacerbating their mental and behavioral health problems (i.e., internalization and total problems). These findings suggest the importance of increased attention and psychological interventions for children in this population. Careful assessments and decisions about children's visits with fathers who are IPV perpetrators are essential to protect and enhance the psychological health of these traumatized children.

\section{Declaration of Interest}

Conflicts of interest: none.

\section{Acknowledgements}

We would like to express our deepest gratitude to the participants and IPV staff that cooperated with this study. Our heartfelt appreciation goes to Ms. Masayo Yoshizaki and Ms. Hatsue Hashimoto for their understanding and assistance with our research. This work was supported by a JSPS KAKENHI Grant-in-Aid for Exploratory Research (grant number 25670964) and the 51 $1^{\text {st }}$ Meiji Yasuda Mental Health Foundation.

\section{References}

[1] World Health Organization (2012) Understanding and Addressing Violence against Women. http://apps.who.int/iris/bitstream/10665/77433/1/WHO_RHR_12.35_eng.pdf

[2] World Health Organization (2013) Global and Regional Estimates of Violence against Women: Prevalence and Health Effects of Intimate Partner Violence and Nonpartner Sexual Violence.

http://apps.who.int/iris/bitstream/10665/85239/1/9789241564625_eng.pdf

[3] Gender Equality Bureau of Japan (2015) National Survey: Act on the Prevention of Spousal Violence and the Protection of Victims. (In Japanese) http://www.gender.go.jp/e-vaw/data/dv-dataH2507.pdf

[4] Vu, N.L., Jouriles, E.N., McDonald, R. and Rosenfield, D. (2016) Children's Exposure to Intimate Partner Violence: A Meta-Analysis of Longitudinal Associations with Child Adjustment Problems. Clinical Psychology Review, 46, 25-33. https://doi.org/10.1016/j.cpr.2016.04.003

[5] Wathen, C.N. and Macmillan, H.L. (2013) Children's Exposure to Intimate Partner Violence: Impacts and Interventions. Paediatrics \& Child Health, 18, 419-422.

[6] Campbell, J.C. and Lewandowski, L.A. (1997) Mental and Physical Health Effects of Intimate Partner Violence on Women and Children. Psychiatric Clinics of North America, 20, 353-374. https://doi.org/10.1016/S0193-953X(05)70317-8

[7] Satyanarayana, V.A., Chandra, P.S. and Vaddiparti, K. (2015) Mental Health Consequences of Violence against Women and Girls. Current Opinion in Psychiatry, 28, 350-356. https://doi.org/10.1097/YCO.0000000000000182

[8] Cody, M.W., Jones, J.M., Woodward, M.J., Simmons, C.A. and Beck, J.G. (2015) Correspondence between Self-Report Measures and Clinician Assessments of Psychopathology in Female Intimate Partner Violence Survivors. Journal of Interpersonal Violence. https://doi.org/10.1177/0886260515589566

[9] Johnson, D.M. and Zlotnick, C. (2012) Remission of PTSD After Victims of Inti- 
mate Partner Violence Leave a Shelter. Journal of Traumatic Stress, 25, 203-206. https://doi.org/10.1002/jts.21673

[10] Helfrich, C.A., Fujiura, G.T. and Rutkowski-Kmitta, V. (2008) Mental Health Disorders and Functioning of Women in Domestic Violence Shelters. Journal of Interpersonal Violence, 23, 437-453. https://doi.org/10.1177/0886260507312942

[11] Vos, T., Astbury, J., Piers, L.S., Magnus, A., Heenan, M., Stanley, L., Walker, L. and Webster, K. (2006) Measuring the Impact of Intimate Partner Violence on the Health of Women in Victoria, Australia. Bulletin of the World Health Organization, 84, 739-744. https://doi.org/10.2471/BLT.06.030411

[12] Scheffer Lindgren, M. and Renck, B. (2008) "It Is Still So Deep-Seated, the Fear": Psychological Stress Reactions as Consequences of Intimate Partner Violence. Journal of Psychiatric Mental Health Nursing, 15, 219-228.

https://doi.org/10.1111/j.1365-2850.2007.01215.x

[13] Amato, P.R. and Kane, J.B. (2011) Parents' Marital Distress, Divorce, and Remarriage: Links with Daughters' Early Family Formation Transitions. Journal of Family Issues, 32, 1073-1103. https://doi.org/10.1177/0192513X11404363

[14] Hetherington, E.M. and Stanley-Hagan, M. (1999) The Adjustment of Children with Divorced Parents: A Risk and Resiliency Perspective. Journal of Child Psychology and Psychiatry, 40, 129-140. https://doi.org/10.1111/1469-7610.00427

[15] Anthony, C.J., Di Perna, J.C. and Amato, P.R. (2014) Divorce, Approaches to Learning, and Children's Academic Achievement: A Longitudinal Analysis of Mediated and Moderated Effects. Journal of School Psychology, 52, 249-261. https://doi.org/10.1016/j.jsp.2014.03.003

[16] Bancroft, L. (2016) When Dad Hurts Mom: Helping Your Children Heal the Wounds of Witnessing Abuse. Meiseki Syoten, Tokyo. (In Japanese)

[17] Bancroft, L. and Silverman, J.G. (2004) DV ni Sarasareru Kodomotats: Kagaisya Toshiteno Oya ga Kazokukinou Nioyobosu Eikyou (The Batterer as Parent: Addressing the Impact of Domestic Violence on Family Dynamics) (Ikushima, S., Trans.). Kongo Shyuppan, Tokyo. (In Japanese)

[18] Straus, M.A. (1979) Measuring Intrafamilial Conflict and Violence: The Conflict Tactics Scales. Journal of Marriage and the Family, 41, 75-88. https://doi.org/10.2307/351733

[19] Umeda, M. and Kawakami, N. (2014) Cross-Cultural Measurement Equivalence of the Japanese Version of Revised Conflict Tactics Scales Short Form among Japanese Men and Women. Psychiatry and Clinical Neurosciences, 68, 804-811. https://doi.org/10.1111/pcn.12194

[20] Zigmond, A.S. and Snaith, R. (1983) The Hospital Anxiety and Depression Scale. Acta Psychiatrica Scandinavica, 67, 361-370. https://doi.org/10.1111/j.1600-0447.1983.tb09716.x

[21] Zigmond, A.S., Snaith, R.P. and Kitamura, T. (1993) Hospital Anxiety and Depression Scale (HADS). Archives of Psychiatric Diagnostics and Clinical Evaluation, 4, 371-372. (In Japanese)

[22] Hatta, H., Higashi, A., Yahiro, H., Ozasa, K., Hayashi, K., Kiyota, K., Inokuchi, H., Ikeda, J., Fujita, K., Watanabe, Y. and Kawai, K. (1998) Validation of the Hospital Anxiety and Depression Scale. Japanese Journal of Psychosomatic Medicine, 38, 309-315. (In Japanese)

[23] Itani, T., Kanbayashi, Y., Nakata, Y., Kita, M., Fuji, H., Kuramoto, H., Negishi, T., Tezyuka, M., Okada, A. and Natori, H. (2001) Standardization of the Japanese Version of the Child Behavior Checklist/4-18. Psyhiatria et Neurologia Paediatrica Japonica, 41, 243-252. (In Japanese) 
[24] Kusanagi, E. (1993) A Psychometric Examination of the Children's Behavior Questionnaire (Annual Report, 1991-1992, No.15). Hokkaido University, Faculty of Education, Research and Clinical Center for Child Development, Sapporo, 25-33.

[25] Hamby, S., Finkelhor, D., Turner, H. and Ormrod, R. (2011) Children's Exposure to Intimate Partner Violence and Other Family Violence. Office of Juvenile Justice and Delinquency Prevention, U.S. Department of Justice, Washington DC.

https://www.ncjrs.gov/pdffiles1/ojjdp/232272.pdf

[26] McFarlane, J.M., Groff, J.Y., O’Brien, J.A. and Watson, K. (2003) Behaviors of Children Who Are Exposed and Not Exposed to Intimate Partner Violence: An Analysis of 330 Black, White, and Hispanic Children. Pediatrics, 112, e202-e207. https://doi.org/10.1542/peds.112.3.e202

[27] Wathen, C.N. and Macmillan, H.L. (2013) Children's Exposure to Intimate Partner Violence: Impacts and Interventions. Paediatrics \& Child Health, 18, 419-422.

[28] Hardesty, J.L., Crossman, K.A., Khaw, L. and Raffaelli, M. (2016) Marital Violence and Co-Parenting Quality after Separation. Journal of Family Psychology, 30, 320330. https://doi.org/10.1037/fam0000132

\section{Submit or recommend next manuscript to SCIRP and we will provide best service for you:}

Accepting pre-submission inquiries through Email, Facebook, LinkedIn, Twitter, etc. A wide selection of journals (inclusive of 9 subjects, more than 200 journals)

Providing 24-hour high-quality service

User-friendly online submission system

Fair and swift peer-review system

Efficient typesetting and proofreading procedure

Display of the result of downloads and visits, as well as the number of cited articles

Maximum dissemination of your research work

Submit your manuscript at: http://papersubmission.scirp.org/

Or contact ojn@scirp.org 